\title{
PARCERIA NA FORMAÇÃO DE PROFESSORES
}

Erineu Foerste

Professor adjunto, Universidade Federal do Espírito Santo, Brasil

\section{O TEMA}

A parceria na educação, mais precisamente na formação de professores, é um objeto bastante recente de pesquisa. No contexto brasileiro, embora se tenha alertado sobre a relevância da construção coletiva de uma política interinstitucional de profissionalização do magistério (Lüdke, 1994 e Gatti, 1996), são poucos os estudos específicos até o momento sobre essa questão. Já na literatura internacional, estão disponíveis produções acadêmicas desde a primeira metade dos anos 90 a respeito da temática..

Debates e estudos sobre a parceria em seu sentido mais amplo remetem aos anos 70 e 80 . Apresentam-na como uma prática de configuração complexa, com significados que emergem de atividades em situações variadas da dinâmica social. Seu conceito e características dependem essencialmente dos sujeitos, do contexto e área em que está sendo utilizada. Vale destacar que de um modo geral ela envolve aspectos relacionados a diversos campos do conhecimento, como o histórico, econômico, social, cultural e político.

Na primeira metade dos anos 90 publicaram-se coletâneas no Reino Unido, em que se analisam aspectos relacionados ao contexto social, princípios e práticas do partenariado na formação inicial e continuada de professores, enquanto uma política do poder público, num quadro de reformas significativas no campo da educação (Furlong et al.,1990; Fullan et al., 1992). Na França em 1993, o Institut National de Recherche Pédagogique - INRP organizou um colóquio sobre parceria educacional. Foram feitas análises de tendências dessa prática social específica a partir de estudos realizados por diferentes grupos de pesquisa, os quais vinham se colocando num movimento de investigação para compreender melhor concepções e experiências concretas desse tipo de parceria no contexto francês. De Québec chegam anais de um colóquio realizado em 1996 pela Association Québécoise Universitaire en Formation des Maîtres AQUFOM, juntamente com o Centre de Recherche sur la Formation et la Profession Enseignante CREFPE, da Universidade Laval, em que se tematiza a parceria e saberes docentes na formação de profissionais do ensino.

A parceria no campo educacional, num sentido significativamente amplo, é apontada como uma prática sócio-cultural emergente. Pode ser considerada uma proposta alternativa para superar a racionalidade burocrática em crise, no processo de formação humana em geral. Os estudiosos da problemática (INRP, 1995; AQUFOM, 1998; Tardif et al., 2001; entre outros) destacam-na como parte de um movimento que busca inserir a instituição escolar e a universidade num complexo processo de construção de novas formas identitárias, requeridas numa época de sucessivas crises sociais, tendência que se acentuou desde os últimos decênios do século XX.

\section{PARCERIA NA FORMAÇÃO DE PROFESSORES}

No final do século $X X$, a parceria encontra um terreno favorável para se difundir enquanto política pública na formação de profissionais do ensino. Esse movimento alinha-se com uma necessidade de se 
repensar as bases sustentadoras do processo de formação docente, compreendido enquanto parte constituidora da profissionalização do magistério e resgate da qualidade do ensino básico (Furlong et al., 1990 e 1996; Fullan et al., 1992; INRP, 1995; AQUFOM, 1998). Mais recentemente, tanto nos órgãos da administração pública, como entre o professorado e no meio acadêmico, parceria é usada como uma possibilidade emergente de colaboração, cooperação, partilha de compromissos e responsabilidades.

A diversidade de termos e significados associados a essa prática deve ser considerado com cuidado, face às questões de poder envolvidas na problemática. Os embates estabelecidos entre governo e professorado, a partir das reformas oficiais, sendo implementadas na educação até o momento, conforme Tardif et al. (2001), estão mostrando um dado que não deveria ser desprezado: quanto mais clareza terminológica e conceptual dispuserem os profissionais do ensino e a academia, tanto mais aumenta sua capacidade de argumentar e negociar com os órgãos da administração educacional, hoje revestidos de uma necessidade voraz de realizar reformas.

Estudiosos mostram que essa prática social está carregada de funções decisivas na implementação de políticas oficiais em educação, principalmente com promessas de profissionalizar o ensino, nem sempre garantindo os direitos dos educadores nas suas lutas por um maior reconhecimento e valorização social de sua atividade profissional.

Desde os anos 90 na Inglaterra (Furlong et al., 1990 e 1996; Fullan et al., 1992) e em Portugal (Amiguinho et al., 1994), a palavra "parceria" passou a ser utilizada com ênfase dentro de um discurso de reformas estruturais, atribuindo papéis considerados inovadores e necessários pela burocracia estatal aos docentes, na formação inicial de professores.

Em países como França e Canadá são observadas algumas especificidades que reportam à própria história da formação de professores desses contextos, mas a emergência da parceria nessa área se assemelha em muitos aspectos às polêmicas sobre reformas educacionais em outros países da Europa e nos Estados Unidos. No dizer de Tardif et al. (2001), que discutem a questão a partir de suas investigações em Québec, em interlocução com diversos pesquisadores do cenário internacional (França, Suíça, Bélgica, Inglaterra, EUA, Brasil), a formação inicial de professores, na realidade, encontra-se no presente momento num terreno escorregadio. Apontam a diversidade de termos que pesquisadores, professores e órgãos de governo estão usando para se referir à parceria e sua relação com a profissionalização docente como um dos pontos mais problemáticos.

Nas últimas décadas as políticas públicas estão fortemente submetidas a interesses econômicos, atribuindo ao Estado novos papéis, com a inserção de novos sujeitos no cenário, sem Ihe tirar prerrogativas de legislar sobre os mais diferentes campos. Assim, cabe questionar com Tardif et al. (2001) se a propalada profissionalização docente, por meio da parceria na formação de professores, está realmente resultando numa maior valorização do trabalho de ensino, resgatando efetivamente a qualidade da escola.

Conforme mostram análises de Smedley (2001), a parceria na formação de professores generalizou-se nos últimos dez anos, apesar dos embates travados entre o poder público e os profissionais do ensino (academia e escola básica). Considera que a produção teórica disponível sobre a problemática é um esforço crítico dos profissionais do ensino e já possibilita levantar questões acadêmicas que vão para além de preocupações com uma caracterização meramente política dessa prática social. 
As publicações sobre a temática consideram que a colaboração entre professores da universidade e profissionais do ensino básico não é uma prática tão recente quanto pode parecer numa primeira vista. Ocorre que os profissionais do ensino básico e da academia vêm trabalhando ao longo do tempo, buscando proporcionar aos estudantes dos cursos de formação inicial de professores nas universidades alternativas de pesquisa (entenda-se prática de ensino) no cotidiano escolar. Até os anos 80 esse trabalho integrado resultava de iniciativas e esforços individuais, geralmente centradas na boa vontade e compromisso de professores de algumas disciplinas do currículo dos cursos de licenciatura e algumas escolas. Raramente a relação estabelecida obedecia a acordos interinstitucionais, com regras negociadas, construídas a partir de reflexões coletivas sobre a prática docente (nas escolas e na universidade). Nessa parceria predominavam pressupostos teórico-práticos que acabavam sobrepondo o saber acadêmico aos saberes práticos dos profissionais do ensino básico.

O quadro começou a mudar a partir da segunda metade da década de 80 . Discussões acumuladas sobre professor reflexivo colocaram a parceria na formação de professores como um importante ganho para o movimento pela profissionalização do ensino.

Na perspectiva oficial, a parceria assumiu características mais formais, com atenção especial por parte do poder público, que passou a se ocupar em estabelecer políticas públicas, sobretudo no processo de formação inicial proporcionado pela universidade, com a definição de normas para a sua implementação. Trata-se da chamada parceria oficial. Através dessa modalidade de parceria, o poder público explicita uma tentativa de resposta ao fato de nos últimos anos crescentemente se reconhecer, não raro graças às pesquisas feitas pela própria universidade, que a academia não tem conseguido apresentar alternativas para a superação de problemas na formação de professores, principalmente na modalidade inicial. As reformas oficiais estão atribuindo novas tarefas à escola básica e seus docentes: a assunção de boa parte do processo da formação inicial de profissionais do ensino.

Em contrapartida a esse movimento de intervenção oficial, os profissionais do ensino da universidade e da escola básica construíram novas possibilidades de trabalho integrado, favorecido por práticas de cooperação. Trata-se da parceria colaborativa. Ela representa um esforço que emerge de ações reflexivas, em que professores da universidade e docentes do ensino básico se articulam a partir de objetivos comuns. Esse movimento busca garantir a indissociabilidade teórico-prática dos currículos dos cursos de formação de profissionais do ensino, tendo como base dispositivos interinstitucionais concretos, negociados coletivamente entre universidade, órgãos da gestão pública (secretarias de educação), sindicatos de professores etc. Isso implica uma postura epistemológica diferenciada, pautada na flexibilização curricular e ação dialógica, que impulsiona a introdução de outros sujeitos, saberes e espaços institucionais alijados ou pouco considerados até então no complexo processo de socialização profissional docente.

Alguns pontos considerados problemáticos nessa modalidade de parceria, que funcionam ainda como barreiras ou forças impeditivas da efetiva colaboração entre a academia e os estabelecimentos de ensino básico, merecem uma maior atenção, diz Smedley (2001). Destacam-se entre eles: a) prevalência de falta de mobilidade ou flexibilidade das instituições envolvidas, principalmente a universidade; b) pouco reconhecimento social do professor e da atividade profissional que exerce acabam interferindo de maneira negativa, chegando a dificultar a continuidade dos trabalhos, inicialmente assumidos com um certo otimismo; c) sobrecarga de trabalho para o professor da escola básica envolvido em projetos desse tipo 
precisa ser considerada com mais cuidado, pois pode levar ao esgotamento dos propósitos de qualquer programa que se proponha a desconstruir práticas consideradas arcaicas ou pouco produtivas, possibilitando o novo emergir na sua plenitude; d) reduzido número de professores na universidade e nas escolas realmente interessados e qualificados para tomarem parte de um projeto dessa dimensão políticoacadêmica é um aspecto negativo que dificulta o desenvolvimento desejável dos programas.

Há diferenças de cultura institucional da universidade e da escola básica que não podem ser desprezadas neste debate. A concepção de profissionalismo docente é o mesmo, se considerarmos os professores da academia e os professores das escolas? A falta de clareza teórico-prática e de estrutura organizacional sustentada interinstitucionalmente, muitas vezes, torna qualquer tipo de inovação fragilizada, produzindo predisposições para descontinuidades e diminuição de entusiasmo dos sujeitos envolvidos.

As reflexões feitas aqui sobre a problemática, partindo do contexto mais abrangente, remetem-nos para um olhar sobre a realidade nacional. O Ministério da Educação e Cultura - MEC tem garantido em documentos reguladores seu interesse pela parceria, sem explicitar claramente como o governo vai prover todas as condições necessárias em termos materiais e humanos requeridas para a implementação dessas mudanças. Uma leitura desses textos oficiais identifica a importância dada à parceria na definição e implementação de políticas de formação inicial e continuada dos profissionais do ensino (MEC/CNE, 2002a e 2002b; MEC, 2003). É recomendada como uma prática necessária no movimento de inovação do processo de formação dos professores como profissionais do ensino. Diante disso cabe perguntar por que só agora a parceria se coloca como uma questão relevante para o governo? Que concepções estão embutidas nesse movimento internacional, que vem sendo introduzido no campo educacional brasileiro desde a segunda metade dos anos 90 ? Até que ponto nossas especificidades serão levadas em consideração, na perspectiva das reformas educacionais oficiais, sobretudo no campo da formação dos profissionais do ensino?

Quando se trata de considerar que a parceria na formação inicial de professores é objeto de interesse do poder público, não se pode descuidar de uma dimensão política importante envolvida na questão. A redefinição dos papéis do Estado nos últimos tempos tem mostrado na prática uma certa vulnerabilidade do poder público no campo das políticas sociais. Observa-se genericamente que os dirigentes estão muito suscetíveis ao humor de diferentes pressões, sejam elas de caráter políticoideológico e/ou econômico. De certa forma, isso escapa do controle dos profissionais do ensino e da universidade, dificultando-Ihes as lutas pela profissionalização do trabalho docente. Se a apropriação da parceria por parte do poder público é feita com promessas de profissionalização do magistério, existem nesse movimento contradições que parecem caracterizar um paradoxo bastante questionável.

De fato há muitas promessas oficiais sendo colocadas a partir das últimas duas décadas para o processo de profissionalização do professor. Isso vem sendo feito essencialmente por meio das já mencionadas reformas educacionais públicas, não raro sem uma efetiva participação do magistério. Pouco vale dar oficialmente um status profissional ao professor, se as condições da qualidade da formação inicial e continuada dos professores não são objeto de uma significativa transformação; pouco se espera também das reformas educacionais do poder público com vistas a um resgate do ensino básico, se não forem consideradas as demandas dos profissionais do ensino por melhores condições de trabalho (carreira, ações públicas de saúde preventiva, reconhecimento social, salário condizente com a função do magistério). Há muita responsabilidade sendo colocada pelo governo nas reformas educacionais àqueles que já estão 
sacrificados por não poderem contar com algumas condições concretas para desenvolver bem seu trabalho docente. O direcionamento da responsabilização pelos graves problemas da educação por parte do poder oficial não está demasiadamente desfocado? O que têm a dizer a respeito os próprios profissionais do ensino?

\section{POSSIBILIDADES E LIMITES DA PARCERIA}

Nossas investigações identificam diferentes universidades desenvolvendo parceria na formação de profissionais de ensino no Brasil. A grande parte delas foram implementadas na última década. As análises, entretanto, permitem situar a Universidade Federal do Mato Grosso - UFMT ${ }^{1}$ como a instituição que tem acumulado experiências de parceria na formação de professores há mais tempo, isto é, desde os anos 70 .

Entre alguns dos principais achados dos estudos feitos sobre a UFMT, podem ser citados: a) o esforço interinstitucional na construção coletiva e implementação de uma política de profissionalização de professores do ensino básico; b) a introdução de outros espaços institucionais na formação de professores; c) a valorização de diferentes saberes, muitas vezes pouco prestigiados pela academia, como os saberes práticos, por exemplo; d) a colaboração de novos sujeitos na discussão, implementação e avaliação de projetos, pouco convencionais no contexto nacional na formação de profissionais do ensino. Trata-se de frentes diferenciadas de qualificação de professores, que aos poucos estão apontando alternativas para superar algumas das principais barreiras que se interpõem historicamente entre a academia e a escola básica na profissionalização do magistério entre nós.

Autores alertam para uma questão que não deveria ser desconsiderada sobre a discussão da parceria na formação de professores a partir da segunda metade dos anos 80 . É preciso saber se está o trabalho docente realmente passando por um processo de crescente revalorização social (Nóvoa, 1991, 1992b, 1998 e 2001; Tardif et al., 2001). De fato a figura do professor está na mira das políticas públicas neste limiar do século, mas encontra condições favoráveis para a sua profissionalização?

O interesse governamental pelo profissional do ensino, que está se fortalecendo em praticamente todos os países capitalistas, precisa ser situado no seio das reformas públicas, que se enquadram na agenda da chamada Nova Direita, num contexto em que se conjugam compromissos neoliberais e forças de mercado, no projeto thatcheriano de Estado e sociedade livres (Gamble, 1988; Whitty, 1989; 1993 e 1998; Torres, 1998a e 1998b; Lüdke e Moreira, 1998; Lüdke et al, 1999).

Nesse movimento político de desregulamentação neoliberal, os governos em diferentes países em todo o mundo passaram a implementar mudanças não só na formação do professor, utilizando como mote a parceria, mas em todo o processo de formação. As entidades de organização docente e a academia entendem esse movimento oficial essencialmente como oposição ao projeto de profissionalização do professor desenvolvido pela universidade, numa longa trajetória de diálogo com o professorado, que tem como base a definição do ofício docente a partir dos debates sobre profissional reflexivo (Wilkin, 1990). Há interesses bastante velados do poder público, no dizer de Whitty (1998) e Goodson (1995 apud Lenoir, 1998), em degradar e mesmo desmantelar todo um conjunto de programas da academia, voltados para a

\footnotetext{
${ }^{1}$ Esta universidade foi fundada em 1970, tendo como sede a cidade de Cuiabá, capital do Estado do Mato Grosso, na região Centro-Oeste do Brasil.
} 
construção da autonomia e identidade do professor como um profissional. São programas construídos ao longo de décadas de experiências e pesquisas.

Analisando alternativas tradicionais e recentes de formação de professores, Bourdoncle (1995 e 1997) afirma que a parceria consiste na articulação entre a universidade e escolas, com intermediação do poder público nos últimos tempos. Destaca que nos EUA fundaram-se estabelecimentos que funcionam com objetivos semelhantes aos hospitais universitários na formação dos profissionais da saúde, as chamadas Professionnal Development School. Mais de cem escolas desse tipo foram criadas logo de saída, na segunda metade dos anos 80. A idéia acabou sendo muito difundida com atividades realizadas pelo chamado Holmes Group, uma comissão que trabalhou na época para a implementação de reformas educacionais, com uma ênfase especial no processo de formação docente. $\mathrm{Na}$ verdade essas escolas remetem-nos a uma tradição de longa data, a das "escolas laboratórios universitários" (colégio de aplicação) dos anos 30, defendidos na Universidade de Chicago por Dewey, as quais serviam de campo para realização de pesquisas educacionais e experiências alternativas de práticas pedagógicas.

Uma experiência inovadora dos anos 90 é encontrada em Québec, com a definição de um espaço interinstitucional por meio da AQUFOM, fundada em 1990, à qual nos referimos anteriormente. Essa entidade articula várias universidades, funcionando como um espaço institucional autônomo que reúne diferentes grupos de profissionais da educação, envolvidos em atividades de formação docente na academia e na escola básica. Em linhas gerais esse espaço interinstitucional nasce para interferir nas políticas oficiais no campo da educação, firmando-se enquanto um canal alternativo de articulação dos interesses dos profissionais da educação, no movimento pela profissionalização do magistério. Pesquisadores, representantes de professores de pelo menos duas centenas de estabelecimentos de ensino básico (comissões de escola), organizações de classe do professorado etc. no Québec fortaleceram posicionamentos que passaram a influenciar de alguma maneira a formação inicial e continuada.

Dessa organização surge a figura do professor associado, recrutado pelas equipes universitárias e por elas formado. O profissional do ensino básico passa a trabalhar em parceria com a universidade na formação inicial de profissionais do ensino (AQUFOM, 1998), participando de pesquisas, dinamizando, desse modo, o processo de socialização profissional a partir da perspectiva colaborativa. Cedo o movimento percebeu que sua missão era a de garantir duas frentes de atuação, a profissional e a científica. O desafio é contribuir com a promoção da qualidade da formação de professores, na perspectiva dos saberes envolvidos na profissão docente.

A AQUFOM constitui-se sem dúvida como um espaço institucionalizado para diálogo entre os pesquisadores e os professores da escola básica, enfim, as equipes das universidades e das escolas e entidades de classe do magistério, bem como com o poder público nas suas diferentes esferas. Está interessada especialmente no professor, na sua formação e desenvolvimento profissional (AQUFOM, 1998). O colóquio de 1996, tematizando especificamente o processo de formação do professor através da colaboração entre escola básica e universidade, foi considerado uma oportunidade para se discutir a formação inicial, no bojo das transformações sociais, políticas e econômicas dos últimos tempos e a emergência de um novo paradigma de socialização profissional para a área.

As discussões de Tardif et al. (2001) consideram que há um risco do movimento de profissionalização docente ser aprisionado pelas forças poderosas que buscam rearticular o poder do capital 
na perspectiva do neoliberalismo. Segundo eles ainda é bastante cedo para dizer com segurança o que realmente pode acontecer. Os debates em torno da profissionalização docente sofre influências diversas, que oscilam entre movimentos conservadores e outros de caráter mais progressista, que defendem uma visão mais crítica da escola, seu funcionamento interno e suas relações com a sociedade. O que é difícil de precisar é se a universidade vai dar conta de responder aos desafios todos postos por diferentes interlocutores nessa problemática. O que ela tem interesse e condições de atender de fato? Em que isso interfere no seu papel construído nos últimos cinqüenta anos na formação de professores? Afinal, em que contribui a profissionalização do ensino se não houver políticas públicas mais efetivas para melhorar a qualidade do processo de ensino e aprendizagem nas escolas?

A partir dos anos 90 a França começa a implementar uma série de políticas públicas na área de formação de profissionais do ensino para criar um corpo único de professores, com o objetivo oficial de revigorar a carreira docente (Crinon, 1995b; Losego, 1995; Chartier, 1998; Altet, 2001). A criação dos IUFM é a principal realização do governo francês com vistas ao processo de recrutamento dos profissionais do ensino básico. Se antes disso havia espaços institucionais específicos, numa escala hierárquica de reconhecimento social dos professores formados para os diferentes níveis da escola básica, agora esse processo sofre uma unificação, com o objetivo de profissionalizar o ensino e imprimir um caráter universitário àqualificação de todos os professores.

Há controvérsias que consideram estar esse movimento fadado a produzir distorções, institucionalizando uma baixa qualidade na formação e recrutamento docente. "Os grupos de pressão, quer do $2^{\circ}$ grau, quer da universidade, costumam denunciar os IUFM como máquinas de nivelar por baixo, a formação dos verdadeiros professores, ou seja os professores, do colégio e do liceu" (Chartier, 1998, p.50). Defendem que está se trocando um saber mais elevado das diferentes disciplinas (uma verdadeira cultura profissional) por quimeras pedagógicas. Porém, na prática, um dos resultados mais concretos, à revelia das polêmicas geradas em torno dessa reforma, foi um afluxo substancial de novos candidatos interessados em se qualificar para o trabalho docente, o que não se verificava fazia muito tempo no contexto francês. Houve também uma melhora significativa no processo de seleção de candidatos, podendo se tornar daqui para frente num trunfo para a profissão docente.

Essa reforma oficial tem como pano de fundo críticas ao modelo disciplinar de formação (centrado na lógica do ensino e mestria de conteúdos disciplinares), defendendo a profissionalização docente (apropriação de competências) como lógica de qualidade do ensino (Altet, 2001). A ênfase da formação passa a dar mais atenção ao campo da prática profissional, com uma significativa valorização dos estágios, tendo a alternância como eixo dinamizador. A formação de conteúdo nas diferentes disciplinas do currículo está sendo levada a uma melhor articulação com a formação profissional no contexto de trabalho do professor de ensino básico, através da construção de competências relacionadas ao trabalho docente. Valoriza-se o como organizar planos, desenvolver e gerir atividades de ensino e fenômenos relacionais, trabalhando em equipe etc. Os estabelecimentos de ensino são reconhecidamente tomados como terreno de formação, tendo os professores veteranos um papel importante a cumprir. Há nesse movimento uma autonomização do estudante no desenvolvimento de suas atividades práticas, construindo itinerários pessoais e individualizados, com mais responsabilidade pela escolha de seus itinerários.

\section{CONSIDERAÇÕES FINAIS}


Os autores se referem à parceria educacional, no seu sentido amplo, como meio de construir saídas negociadas coletivamente para questões concretas não resolvidas ao longo do tempo, geradoras de impasses e sensação de impotência dos sujeitos e instituições. Daí se dizer também que o partenariado é um movimento que se coloca a serviço da resolução de problemas, decorrentes de momentos de crise ou estagnação. Tomando especificamente a parceria ou colaboração interinstitucional na formação dos profissionais do ensino, observa-se que ela tem se configurado como uma tendência, no dizer de Smedley (2001), na qual sujeitos e instituições estabelecem relações, tendo na sua base um conjunto complexo e muitas vezes difuso de interesses e de ações, que têm favorecido práticas de negociação, com definição e assunção de compromissos e partilha de riscos.

A parceria na formação de professores traz basicamente um trabalho articulado entre a universidade e as escolas, nem sempre apresentando intermediação do poder público e/ou outras organizações da sociedade civil (Bourdoncle, 1997). A priorização dessa tendência se evidencia com maior força sobretudo a partir dos anos 90, quando adquire impulso o processo de globalização, em cujo movimento a educação não tem passado despercebida por parte das lideranças políticas. Discursos e práticas sobre parceria na formação docente apresentam uma perspectiva que interessa especialmente ao processo de profissionalização do magistério. Abrem-se importantes possibilidades para ampliar de maneira institucionalizada a participação de docentes em exercício na formação inicial dos professores e realização de pesquisas educacionais.

Segundo Furlong et al. (1992 e 1996) a parceria possibilita, à revelia dos interesses oficiais, dar suporte ao debate entre os profissionais da educação, debate esse que busca superar o tratamento hierárquico atribuído aos saberes na formação inicial de professores, os chamados conhecimentos teóricos e conhecimentos práticos. Essa perspectiva perpassa de maneira significativa as reformas educacionais brasileiras nos últimos dez anos, especialmente no que se refere à formação dos profissionais do ensino básico.

A academia foi acumulando pesquisas sobre a unidade indissociável entre conhecimentos acadêmicos e conhecimentos da prática docente, requerendo outros pressupostos epistêmicos na formação profissional do professor. Esses saberes do campo educacional apresentam cada um deles uma lógica própria de organização, a partir de instituições com papéis bastante diferenciados entre si. Mesmo assim não se trata de organizações institucionais que não possam trabalhar de forma colaborativa com vistas à profissionalização do professorado. Nesse sentido destaca-se, tanto na perspectiva do discurso dos professores como do poder público, a importância da parceria na formação dos profissionais do ensino, enquanto uma prática de colaboração construída na interface entre universidade e professores da escola básica.

Em suas análises sobre profissão e profissionalização docente, Nóvoa (1992a e 1992b) refere-se à relevância e centralidade no presente momento da configuração de uma nova "profissionalidade docente", com uma maior valorização da cultura da profissão docente, bem como da cultura organizacional das escolas. Nesse sentido a socialização profissional do professor, compreendida como articuladora dos momentos de formação e exercício da atividade de ensino, como mostram os estudos de Lüdke (1996a, 1996b, 1996c e 1998), assume uma dimensão que coloca a instituição escolar como um espaço indispensável para uma integração efetiva entre e a teoria e prática nos cursos de formação inicial e continuada de profissionais do ensino. 
Dessa maneira ambos os autores criticam a racionalidade técnica, que assumiu características específicas na formação acadêmica de professores ao longo das últimas décadas. Observa-se uma hierarquização dos conhecimentos, com hipertrofia do conhecimento legitimado academicamente (a chamada teoria), em detrimento dos saberes adquiridos pelo professor no exercício de sua profissão. De um modo geral tem se desprezado o pressuposto que mostra ser a atividade educativa um processo diferenciado do ponto de vista epistemológico, não coincidindo necessariamente com a organização e a dinâmica da formação acadêmica (Tardif e Lévesque, 1998; Tardif, 2000), muito valorizada ao longo do tempo nos projetos mais tradicionais de formação de professores.

A parceria ajuda a fortalecer uma concepção segundo a qual a formação é um campo privilegiado para produzir a profissão docente. Todavia, uma articulação efetiva com a escola e seus profissionais, o campo profissional por excelência do trabalho docente, não pode ser desconsiderada como uma alternativa dinamizadora da formação inicial, proporcionada tradicionalmente pela universidade. E isso não se dá por decreto.

Nesse enfoque, a formação inicial e continuada de professores torna-se objeto da busca coletiva de novas alternativas organizacionais e institucionais, nas quais esses profissionais são qualificados e contratados. A base desse movimento tem como objetivo assentar a formação docente em pressupostos que consideram a atividade reflexiva do professor sobre sua formação e prática, como condições fundamentais do processo de socialização docente, enfim, da construção da identidade profissional do magistério.

Desse modo a parceria é uma prática bem sucedida, na perspectiva da resolução de problemas locais na área de formação de professores, como ficou evidenciado no estudo da literatura disponível sobre a temática, bem como das análises sobre aspectos da Licenciatura em Educação Básica: Séries Iniciais do Ensino Fundamental na Modalidade EAD, em desenvolvimento na UFMT desde 1995. Por meio de diferentes canais de colaboração, em que o Grupo de Trabalho Interinstitucional - GTI cumpre um papel político articulador básico na garantia de algumas condições para a profissionalização do professor da escola básica, verifica-se, com ênfase na atividade do orientador acadêmico, que o modelo tradicional de currículo desenvolvido pela universidade na licenciatura não atende mais às demandas de formação inicial e continuada dos profissionais do ensino.

Pela literatura analisada e pela abordagem de dados, a partir das experiências da UFMT, pode-se afirmar que está em curso uma prática com sustentação interinstitucional, que aos poucos vem resultando numa certa ruptura em relação à racionalidade técnica na formação de professores na universidade. Essa constatação reforça a idéia de que a profissionalização do professor beneficia-se com um movimento de construção coletiva de novos patamares teóricos e práticos, em que os saberes da experiência passam a se constituir como eixo básico de uma nova epistemologia no processo de socialização profissional docente. A valorização curricular da prática coloca necessariamente na berlinda a tradição epistemológica significativamente longa, que tem servido de sustentação ao projeto de formação inicial dos profissionais do ensino na universidade, tradição essa que é observada também, via de regra, em cursos dos mais diferentes campos do saber com que lida a academia.

\section{BIBLIOGRÁFICAS}


ALTET, Marguerite. As competências do professor profissional: entre conhecimentos, esquemas de ação e adaptação, saber analisar. In: PERRENOUD, P. et al. Formando professores profissionais: quais estratégias? Quais competências? Porto Alegre: Artmed, 2001, pp. 23-35.

Amiguinho, Abílio et al. ESE de Portoalegre e centro de formação: uma experiência de parceria. In: AMIGUINHO, A. e CANARIO, R. (Org.). Escolas e mudança; o papel dos Centros de Formação. Lisboa: Educa, 1994, pp. 13-58.

AQUFOM. Enseignants de métier et formation initiale; des changements dans les rapports de formation à l'enseignement. Paris/Bruxelles/Sherbrooke: AQUFOM/De Boek Université, 1998.

BOURDONCLE, Raymond. Regards sur le partenariats en Europe. In: INRP. Établissements et partenariats: stratégies pour des projets communs. Paris: INRP, 1995, pp. 119-121.

. Normalisation, academisation, universitarisasion, partenatiat: de la diversité des voies vers I'université. Revista da Faculdade de Educação. São Paulo: FE/USP, 23 (1/2): 29-48, jan./dez. 1997.

ChARTIER, Anne-Marie. A formação de professores na França e a criação dos Institutos Universitários de Formação de Mestres. In: PUC-SP. Novas política educacionais: críticas e perspectivas. São Paulo, PUC-SP, 1998, pp. 49-71.

CRINON, Jacques. Le partenariat: pour former ou pour gérer? In: INRP. Établissements et partenariats: stratégies pour des projets communs (Actes du colloque). Paris: INRP, 1995a, pp. 132-138.

Partenariat et formation des maîtres; le discours de l'institution. Recherche e Formation, n. 19, 1995b, pp. 81-102.

DUBAR, Claude. La socialisation: constructions des identités sociales e profissionnelles. Paris: A. Colain, 1991.

. Formes identitaires et socialisation profissionnelle. Revue Française de Sociologie, v. 33, pp. 505529, 1992.

FULLAN, Michael et al. Teacher development and education change. London/Waashington: Falmer Press, 1992.

FURLONG, John. et al. Partnership in initial teacher training. Londres: Cassel, 1990.

Re-defining patnership: revolution or reform in initial teacher education? Journal of Education for Teaching. Londres, 22 (1): 39-55, 1996.

GATTI, Bernadete. Análises com vistas a um referencial para política de formação de professores para o ensino básico. Brasília: CONSED, 1996.

Huberman, Michaël. O ciclo de vida profissional dos professores. In: NÓVOA, A. (Org.). Vidas de professores. Porto: Porto Editora, 1992, pp. 31-62.

INRP. Établessements partenariats: stratégies pour des projets comuns. Paris: INRP, 1995.

LENOIR, Yves. Thème 1: Enjeux sociaux et politiques du partenariat univérsité-milieu scolaire dans la formation des maîtres: quelques questions. In: DILLON, D. et ROY, J. (dir.), L'université et le milieu scolaire: partenaires en formation des maîtres. Actes du troisième Colloque de l'AQUFOM. Montreal: Université McGill, 1995, pp. 25-29. 
LOSEGO, Les conditons politiques de la professionalité enseignante et leurrs consequences sociales. Recherche et Formation, n. 19, 1995, pp.5-24.

LÜDKE, Menga. A socialização profissional de professores, em meio a interdependências e indeterminações. In.: BICUDO, M. A. V. e SILVA, C. A. da (Orgs.). Formação do professor - vol. 1. São Paulo: UNESP, 1996a, pp. 81-89.

Formação inicial e construção da identidade profissional de professores do $1^{\circ}$ grau. In: SCHEIB, Leda et al. (Orgs.) Anais do VIII ENDIPE. Florianópolis - SC: UFSC, 1996b, p. 311 - 321.

A socialização profissional de professores, em meio a interdependências e indeterminações In: BICUDO, M. A . (Org.). Formação de professores. São Paulo: UNESP, 1996c, pp. 81-89.

Sobre a socialização profissional de professores. Cadernos de Pesquisa, São Paulo, no 99, pp. 515, nov., 1996d.

A socialização profissional de professores - III etapa: As instituições formadoras. Rio de Janeiro: PUC-Rio, 1998.

LÜDKE, Menga e MOREIRA, Antônio Flávio. Propostas recentes para a reforma da formação de professores no Brasil. Rio de Janeiro: PUC/UFRJ, 1998.

LÜDKE, Menga. et al. Repercussões de tendências internacionais sobre a formação de nossos professores. Educação e Sociedade, ano XX, n. 68, pp. 278-298, dez. 1999.

. O professor e a pesquisa. Campinas: Papirus, 2001.

LÜDKE, Menga. e WALL, Yara. Professores iniciantes avaliam sua licenciatura. Rio de Janeiro: PUC-Rio, 1983.

MEC/CNE. Resolução no 1/2002. Brasília: CNE, 2002a.

Resolução no 2/2002. Brasília: CNE, 2002b.

MEC. Portaria no 1.403/2003. Brasília: Gabinete do Ministro, 2003.

NóvoA, Antonio. Para o estudo sóci-histórico da gênese da profissão docente. Teoria e Educação, n. 4, pp. 109-139, 1991.

.Formação de professores e profissão docente. In: NÓVOA, Antonio. (Org.). Os professores e sua formação. Lisboa: Dom Quixote, 1992a, pp.15-33.

. O passado e o presente dos professores. In: NÓVOA, Antonio. (Org.). Profissão professor. Porto: Porto Editora, 1992b, pp. 13-30.

História da profissão docente: desafios para a pesquisa. Rio de Janeiro: PUC-Rio, 1998 (Palestra proferida em 25 de agosto de 1998).

. O futuro presente dos professores: dilemas da profissão e da formação docente. In. UFF. Simpósio Internacional: crise da razão e da política na formação docente. Niterói, UFF/CNPq/Editora Ágora da Ilha, 2001 (Conferência de abertura).

SMEDLEY, Lea. Impediments to partnership: a literature review of school-university links, Teachers and Teaching: Theory and Practice, 7 (2): 189-209, jun., 2001. 
TARDIF, Maurice. Saberes profissionais dos professores e conhecimentos universitários: elementos para uma epistemologia da prática profissional dos professores e suas conseqüências em relação à formação para o magistério. Revista Brasileira de Educação. 13, jan./abr., pp. 5-24, 2000.

TARDIF, Maurice et al. Formação dos professores e contextos sociais; perspectivas internacionais. Porto: Rés-editora, 2001.

TARDIF, Maurice. e LÉVESQUE, M. Conclusion. In: AQUFOM. Enseignants de métier et formation intiale; des changements dans les rapports de formation à l'enseignement. Paris/Bruxelles/Sherbrooke: AQUFOM/De Boeck Université, 1998, pp. 267-279.

TORRES, Rosa Maria. Melhorar a qualidade da educação básica. In: TOMMASI, L. de et al. (Orgs.). O Banco Mundial e as políticas educacionais. São Paulo: Cortez, 1998a, pp.125-193. . Tendência da formação docente nos anos 90. In: PUC-SP. Novas política educacionais: críticas e perspectivas. São Paulo, PUC-SP, 1998b, 173-191.

WHITTY, Geoff. The new right and the National Curriculum: State control or market forces? Journal of Education Policy, 4 (4): 329-341, 1989.

. Education reform and teacher education in England in the 1990s. Journal of Education for Teaching, Oxfordshire, Engl., 19 (4/5): 263-275, out./dez., 1993.

. Controle do currículo e quase-mercados; A recente reforma educacional na Inglaterra e no país de Gales. In: PUC-SP. Novas políticas educacionais: críticas e perspectivas. São Paulo: PUC-SP, 1998, pp.193-213.

WILKIN, Michael et al. The development of partnership in the United Kingdom. In: FURLONG, John. et al. Partnership in initial teacher training. Londres: Cassell, 1990, pp. 3-23. 


\title{
Contactar
}

Revista lberoamericana de Educación

\author{
Principal OEI
}

